\title{
FE Analysis of FGM Plates on Arbitrarily Orthotropic Pasternak Foundations for Membrane Effects
}

\author{
Ülkü Hülya ÇALIK-KARAKÖSE ${ }^{1}$
}

\begin{abstract}
In this study, the finite element analysis of sigmoid functionally graded material (S-FGM) plates resting on orthotropic Pasternak elastic foundations with different material angles is presented. For modelling, SAP2000 software package is used in which the required adjustments are made to obtain the expected behaviour of the plate-foundation system. The plate is modelled using both solid elements and layered shell elements by defining a number of solid elements and layers in the thickness direction having elastic properties equivalent to the properties of the S-FGM plate. The interaction between the plate and the foundation is provided by equalizing the vertical displacements of the plate and foundation nodal points. The orthotropic Pasternak foundation is modelled using plane strain elements with some adjustments to the elastic properties. The membrane effects of the simply supported S-FGM plate on Pasternak foundation are considered by defining the edge boundaries of the system as pinned supports. These effects are excluded by converting all boundary nodes into roller supports except for one of the corner nodes of the plate and the foundation due to the stability requirement. A number of verification examples are performed to demonstrate the convenience and robustness of the proposed model. This work can be easily extended to static and dynamic analyses of FGM plates with various geometries resting on arbitrarily orthotropic Pasternak elastic foundations for further studies.
\end{abstract}

Keywords: Functionally graded material plates, membrane effects, orthotropic Pasternak foundation, material angle.

\section{INTRODUCTION}

Functionally graded materials (FGMs) are heterogeneous materials in which the material properties are varied continuously in the thickness direction as presented by Suresh and Mortenson [1], and are used to improve the strength and stiffness of structural elements in many engineering applications. In laminated composites which are used to satisfy the desired high-performance demands, stress singularities may occur at the interface of two

Note:

- This paper was received on February 12, 2021 and accepted for publication by the Editorial Board on October 22, 2021.

- Discussions on this paper will be accepted by May 31, 2022.

- https://doi.org/10.18400/tekderg.878982

1 Department of Civil Engineering, Istanbul Technical University, Istanbul, Turkey calikkarakose@itu.edu.tr - https://orcid.org/0000-0002-2944-7434 
different materials which may cause de-bonding or cracking. This problem is eliminated by the gradual change of the material properties of the functionally graded materials. Studies on FGMs were first made for thermal barriers by Koizumi [2] and thermal mechanical behaviour of FGMs was investigated in $[3,4]$.

Reddy [5] presented theoretical formulation and finite element models of functionally graded rectangular plates based on the third-order shear deformation theory. Cheng and Batra [6] derived field equations for a functionally graded plate using both first-order and third-order shear deformation theories.

Three different homogenization methods are used to describe the variation of material properties; namely power law $[7,8]$, exponential $[9,10]$ and sigmoid functions. Since the material properties vary continuously but rapidly and stress concentrations appear in one of the interfaces in both the power-law and exponential functions, Chung and Chi [11] defined a new volume fraction proposing an S-FGM, which was composed of two power-law functions. It is demonstrated that the stress intensity factors of a cracked body are significantly reduced by Chi and Chung [12] through the use of an S-FGM,. Chi and Chung [13] derived theoretical formulations of a simply supported rectangular FGM plate of medium thickness subjected to transverse loading and numerical solutions were obtained by using the formulations derived by Chi and Chung [13], and also checked by the finite element method in Chi and Chung [14]. The coupling effect of extension and bending in functionally graded plates under transverse loading was investigated by Orakdöğen et.al.[15] using the finite element method. Zenkour [16] introduced the bending analysis of a simply supported functionally graded rectangular plate subjected to a transverse uniform load. Elishakoff et.al.[17] presented the static response of a three-dimensional functionally graded material rectangular plate with clamped boundary conditions and a power-law distribution of the mechanical properties is adopted in the modelling. Swaminathan et.al.[18] presented an extensive review of the various methods used in studying the static, dynamic and stability behaviours of FGM plates where analytical and numerical methods are both considered.

Plates resting on elastic foundations have been widely studied by many researchers to be used in modelling various engineering applications. The simplest elastic foundation model is the Winkler or one-parameter model by Winkler [19] in which the interaction between the plate and the foundation is represented by a series of independent vertical linear elastic springs. A more realistic representation of the elastic medium is made with two-parameter or Pasternak model by Pasternak [20] which has a second dependent parameter that introduces the shear interaction between springs avoiding the deflection discontinuity on the interacted surface of the plate.

There exist many studies performing the static analysis of isotropic rectangular plates resting on isotropic Pasternak foundations [21,22] and vibration analysis of this type of plate-foundation system [23-26]. Shen [27] carried out the post-buckling analysis of a simply supported, composite laminated rectangular plate resting on an isotropic twoparameter elastic foundation where the plate is subjected to in-plane loading. Huang et.al. [28] presented exact solutions for functionally graded thick plates based on the threedimensional theory of elasticity and examined interactions between the Winkler-Pasternak elastic foundation and the plate demonstrating that elastic foundations have significant effect on the mechanical behaviour of functionally graded thick plates. Lee et.al. [29] 
developed a refined higher order shear and normal deformation theory for the bending analysis of power law, exponential and S-FGM plates resting on isotropic Pasternak foundations. Vibration analysis of isotropic FGM plates on isotropic two-parameter foundations is also performed by many researchers, [30-33]. Mansouri and Shariyat [34] performed the analysis of orthotropic FGM plates on elastic foundations in their paper. In $[35,36]$, seismic behaviour of a 3D structural system resting on a two-parameter elastic foundation was analysed using SAP2000. In the modelling of the foundation, the part of the governing equation that belongs to Winkler behaviour is represented by elastic springs and the part that belongs to elastic shear layer is taken into account by using four-noded quadrilateral finite elements with four degrees of freedom.

There are also studies in the literature on the analysis of homogeneous plates and FGM plates resting on orthotropic Pasternak foundations [37-42]. In this paper, the finite element analysis of S-FGM plates resting on orthotropic Pasternak elastic foundations with different material angles is presented and coupling effect of extension and bending is investigated. SAP2000 software package, [43] is used in the implementation process and some adjustments are made to the software for the expected behaviour of the plate-foundation system. S-FGM plate is first modelled using layered shell elements by defining a number of layers in the thickness direction having elastic properties equivalent to the properties of the S-FGM plate. The plate is also modelled using solid elements. The membrane forcebending moment coupling effect of the simply supported S-FGM plate is considered by assigning the edge boundary nodes as pinned supports.

The interaction between the plate and the foundation is provided by equalizing the plate and corresponding foundation nodal point vertical displacements. Orthotropic Pasternak foundation is modelled using plane strain elements with some adjustments to the elastic properties. After verifying the proposed model with a number of examples taken from the literature, the influence of the material properties, membrane effects, number of layers used for FGM plate and material angles of the orthotropic Pasternak foundation on deflections and stresses are examined with numerical examples.

\section{MATERIAL PROPERTIES OF S-FGM PLATES}

In Figure 1, an S-FGM plate example is shown where $\mathrm{z}$ axis is in the thickness direction and originated at the middle surface of the plate. The material properties vary continuously and functionally based on the volume fraction of the sigmoid distribution.

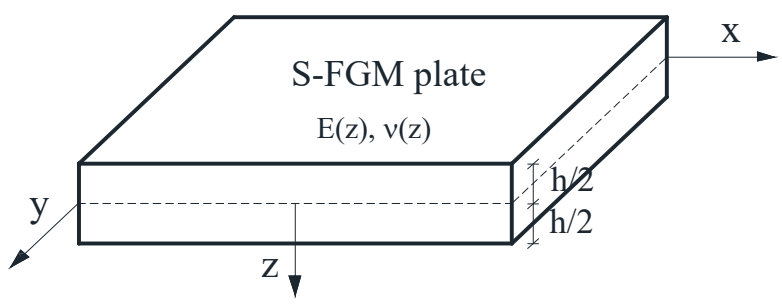

Figure 1 - An S-FGM plate example 
The volume fraction for S-FGM is defined using two power-law functions to ensure smooth distribution of stresses among all interfaces of the plate, Chung and Chi [11]. The two power-law functions are defined by

$$
\begin{array}{lll}
V_{1}(z)=1-\frac{1}{2}\left(\frac{\frac{h}{2}-z}{\frac{h}{2}}\right)^{p} & \text { for } & 0 \leq z \leq \frac{h}{2} \\
V_{2}(z)=\frac{1}{2}\left(\frac{\frac{h}{2}+z}{\frac{h}{2}}\right)^{p} & \text { for } & -\frac{h}{2} \leq z \leq 0
\end{array}
$$

where $\mathrm{p}$ is the material exponent. The elastic modulus of the S-FGM can be calculated using

$$
\begin{array}{llr}
E(z)=V_{1}(z)\left(E_{1}-E_{2}\right)+E_{2} & \text { for } & 0 \leq z \leq \frac{h}{2} \\
E(z)=V_{2}(z)\left(E_{1}-E_{2}\right)+E_{2} & \text { for } & -\frac{h}{2} \leq z \leq 0
\end{array}
$$

Here, $E_{1}$ and $E_{2}$ are the elastic moduli of the bottom and top surfaces of the plate, respectively. The Poisson's ratio is assumed to be constant since it is stated by Delale and Erdogan [9] that its effect on deformation is much less than that of the elastic modulus.

\section{FINITE ELEMENT MODELLING}

\subsection{S-FGM Plate Model}

The S-FGM plate is first modelled using shell finite elements for which the section type is defined as "Shell-Layered/Nonlinear" in SAP2000, consisting of a number of layers in the thickness direction. Each layer has a constant elastic modulus value which is pre-calculated using the functions given in Eqs. [1]-[4] representing the continuous variation of the elastic modulus of the plate starting from the bottom surface. The distance parameter " $z$ " in the functions indicates the ordinate of the middle section of each layer. In Figure 2, a segment of an S-FGM plate and its equivalent representation with 8 layers is shown.

The shell element in the software is a four-noded finite element and its formulation combines membrane and plate-bending behaviours. The element always activates all six degrees of freedom which are 3 translations and 3 rotations at each of its connected joints. When the element is used as a pure plate, it must be ensured that restraints or other supports are provided to the degrees of freedom for in-plane translations and the rotation about the normal.

The layered shell allows any number of layers to be defined in the thickness direction, each with an independent location, thickness, behaviour, and material. For bending, a Mindlin formulation is used which always includes transverse shear deformations. Membrane and plate behaviours will be coupled if the layering is not symmetrical in the thickness direction and the edge boundaries are assigned as pinned supports. 
The S-FGM plate is also modelled using solid elements where the elastic modulus of each solid element in the thickness direction is equal to the elastic modulus of the corresponding layer of the shell element.

The solid element used is an eight-noded finite element with three translational degrees of freedom at each joint. Rotational degrees of freedom are not activated. This element contributes stiffness to all of these translational degrees of freedom.

The membrane effects appear in the simply supported S-FGM plate when the edge boundary nodes of the plate are assumed to be pinned supports (no horizontal displacement) whereas these effects are excluded by converting all boundary nodes into roller supports except at one of the corner nodes due to the stability requirement.

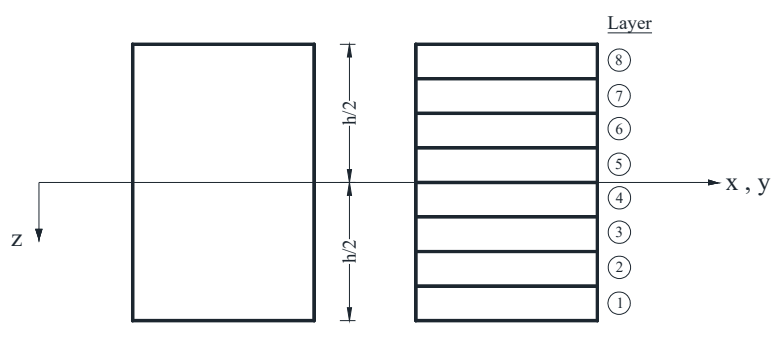

Figure 2 - A segment of an S-FGM plate and equivalent representation with 8 layers

\subsection{Isotropic and Orthotropic Pasternak Foundation Models}

Isotropic and orthotropic Pasternak foundations are also modelled using SAP2000. The material symmetry type of the isotropic soil element is selected as "orthotropic" so as to change the shear modulus values. All material properties are assigned to zero except the shear moduli $\mathrm{G}_{13}$ and $\mathrm{G}_{23}$ that represent the second parameter of the Pasternak foundation.

The finite element to be used in modelling the Pasternak foundation is defined as "shell" element, the section type is selected as "Plane-Strain" and the thickness is assigned a unit value, $[44,45]$.

The plane strain element is one type of area objects and is used to model plane-strain behaviour in two-dimensional solids. It activates the three translational degrees of freedom at each of its joints. Rotational degrees of freedom are not activated. The plane-strain element models shear that is normal to the plane of the element, in addition to the in-plane behaviour. Thus, stiffness is created for all three translational degrees of freedom.

In the case of plane strain, when the elastic moduli and Poisson's ratios in three directions are defined as zero and the in-plane shear moduli in the two directions $\left(\mathrm{G}_{13}\right.$ and $\left.\mathrm{G}_{23}\right)$ are assigned to non-zero values, only shear stresses in the thickness direction of the element and end forces in the vertical direction appear. When the in-plane shear moduli are assigned to the shear moduli of the two-parameter foundation, the resulting element stiffness matrix is converted into the element stiffness matrix of the two-parameter orthotropic soil element. If the in-plane shear moduli of the soil element are assigned to the same values, the stiffness matrix of the isotropic soil element is obtained. The unknowns are only the deflections of the nodal points. 
The first parameter of the Pasternak foundation which is represented by springs is taken into account as "area springs" assigned to the surface of the foundation.

For the orthotropic foundation model with different material angles, shear moduli $\mathrm{G}_{13}$ and $\mathrm{G}_{23}$ are assigned to different values and a desired material angle is selected.

\subsection{Interaction between Plate and Pasternak Foundation}

The plate-foundation interaction is provided by matching the vertical displacements of the plate and the corresponding foundation nodal points. "Equal constraint" property is used for this purpose where the number of constraints is equal to the number of nodes of the plate. Each constraint is then assigned to the respective plate and foundation nodes.

The S-FGM plate model of the system is created using both layered shell and solid elements as shown in Figure 3.

The membrane effects are excluded by releasing the in-plane translational degrees of freedom of both the plate and foundation edge nodes. Note that the in-plane translations of one of the corner nodes of the plate and the foundation are restrained for the stability requirement.

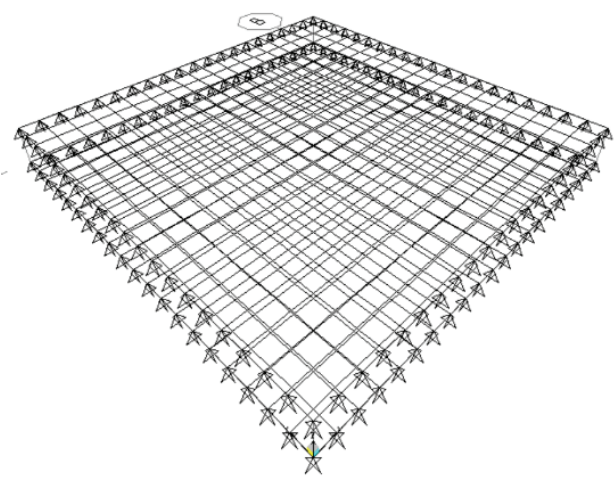

a)

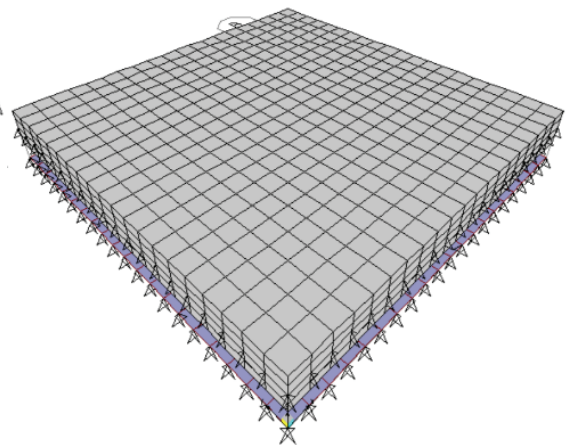

b)

Figure 3 - Plate-foundation finite element model with membrane effects

a) using layered shell finite elements for the plate b) using solid finite elements for the plate

\section{VERIFICATION EXAMPLES}

\subsection{Simply supported S-FGM Plate}

A simply supported square S-FGM plate which has been solved both analytically by Chi and Chung [14] and numerically by [14,15] is analysed and the results are compared only with the results of Orakdöğen et.al.[15] because membrane effect analysis was not carried out by Chi and Chung [14]. The thickness of the plate is $h=0.02 \mathrm{~m}$, the length is $\mathrm{a}=1 \mathrm{~m}$ and the Poisson's ratio is $v=0.3$. The elastic modulus at the bottom surface is $E_{1}=25 \times 10^{6}$ $\mathrm{kN} / \mathrm{m}^{2}$ and the material exponent is $\mathrm{p}=2$. The plate is subjected to a uniformly distributed 
load of $\mathrm{q}=100 \mathrm{kN} / \mathrm{m}^{2}$. The problem is solved for two different elastic modulus ratios, $E_{1} / E_{2}=30$ and $E_{1} / E_{2}=2$ where $E_{2}$ indicates the elastic modulus of the top surface.

First, the plate is modelled using 8 layered shell finite elements and $(4 \times 4),(8 \times 8)$ and (20x20) meshes for $\mathrm{E}_{1} / \mathrm{E}_{2}=30$, including membrane effects. This mesh refinement shows that convergence to the deflections along the $\mathrm{x}$ direction $($ at $\mathrm{y}=0.5 \mathrm{~m}$ ) obtained by Orakdöğen et.al.[15] is achieved using an $(8 \times 8)$ mesh, Figure 4. However, due to one-toone comparison of nodal values, the same mesh discretization with Orakdöğen et.al.[15] which is a (20x20) mesh has been used in the analyses.

The same example is also solved using 2 and 4 layered shell elements to see if the results change with the number of layers used in the modelling. It is observed that for the case $E_{1} / E_{2}=2$, the dimensionless deflections are almost the same for all number of layers both for the plate with and without membrane effects, Figure 5.

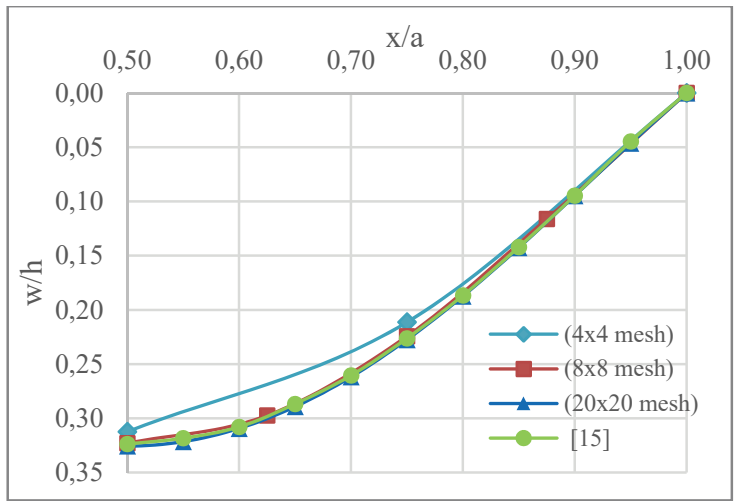

Figure 4 - Variation of dimensionless deflections with mesh refinement (membrane effects are included)

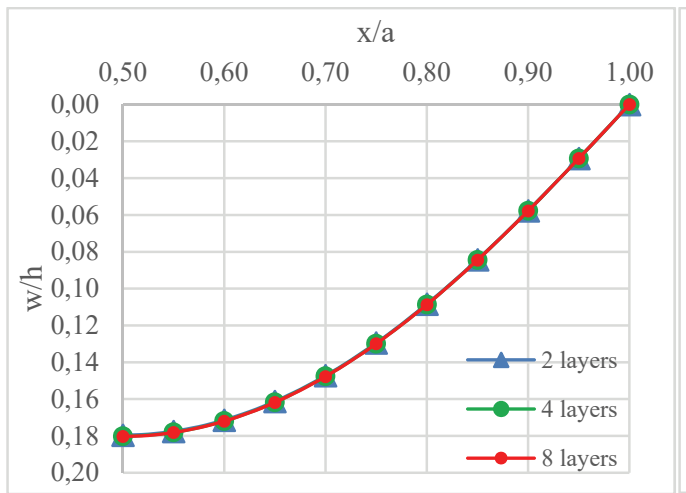

a)

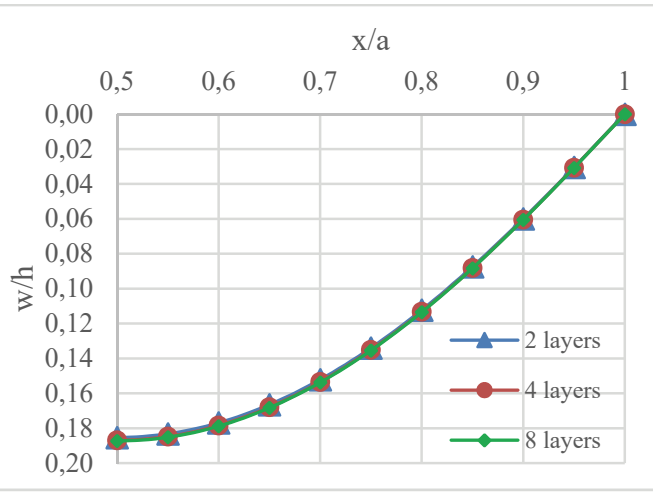

b)

Figure 5 - Comparison of dimensionless deflections for different number of layers $\left(E_{1} / E_{2}=2\right)$

a) membrane effects are included b) membrane effects are excluded 
On the other hand, the dimensionless deflections of the plate with elastic modulus ratio $E_{1} / E_{2}=30$ increase as the number of layers used increases and this difference becomes much larger when the membrane effects are excluded as shown in Figure 6.

The dimensionless deflections of the S-FGM plate along the $\mathrm{x}$ direction (at $\mathrm{y}=0.5 \mathrm{~m}$ ) for the two elastic modulus ratios and for the cases with and without membrane effects (m.e.) are obtained and compared with the solution given by Orakdöğen et.al.[15], Figure 7. Note that 8 layers are used in the modelling while the number of layers used is 10 in Orakdöğen et.al.[15]. It is verified that the results obtained in this study have very good agreement with the reference solution.

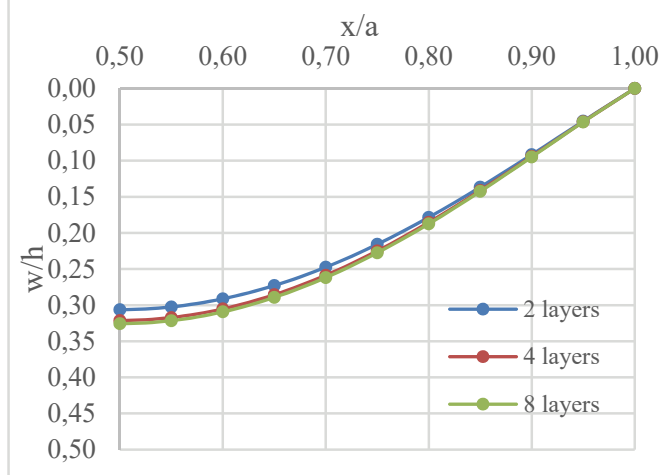

a)

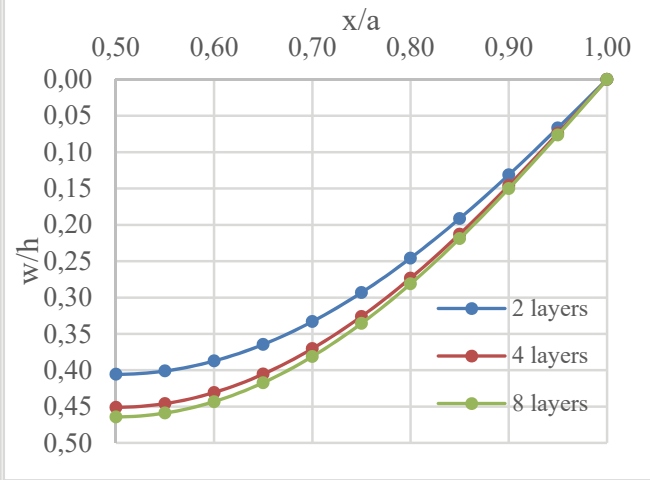

b)

Figure 6- Comparison of dimensionless deflections for different number of layers $\left(E_{1} / E_{2}=30\right)$

a) membrane effects are included b) membrane effects are excluded

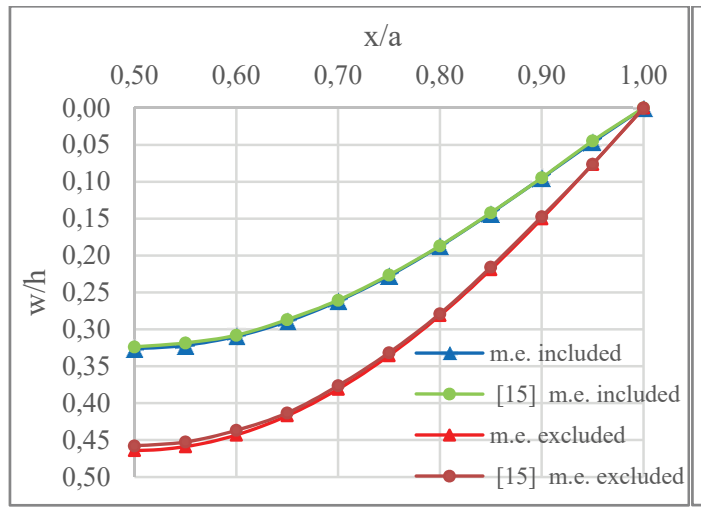

a)

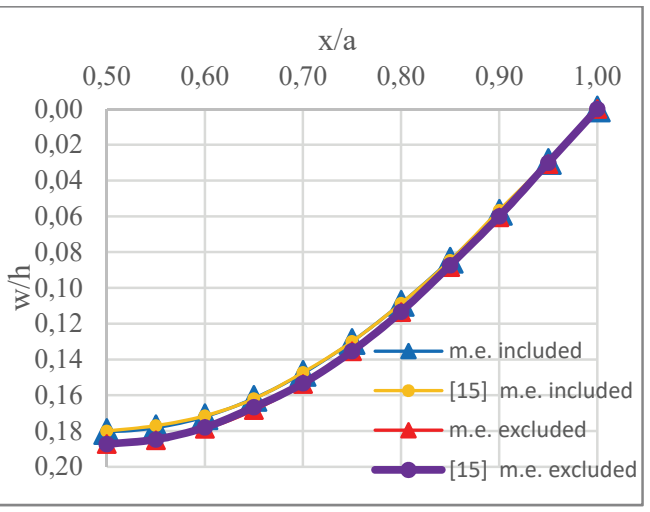

b)

Figure 7 - Comparison of dimensionless deflections

a) $E_{1} / E_{2}=30$ b) $E_{1} / E_{2}=2$ 
The example is modelled and solved using solid finite elements as well and the dimensionless deflections are compared with the values obtained using the model with layered shell elements. It is observed that solid elements can also be used for the modelling since all results match, Figure 8. It is also obtained that the mid-point deflections increase 1.8 times and 2.5 times for the cases with and without membrane effects, respectively as the elastic modulus decreases with a larger ratio from the bottom to the top surface of the plate.

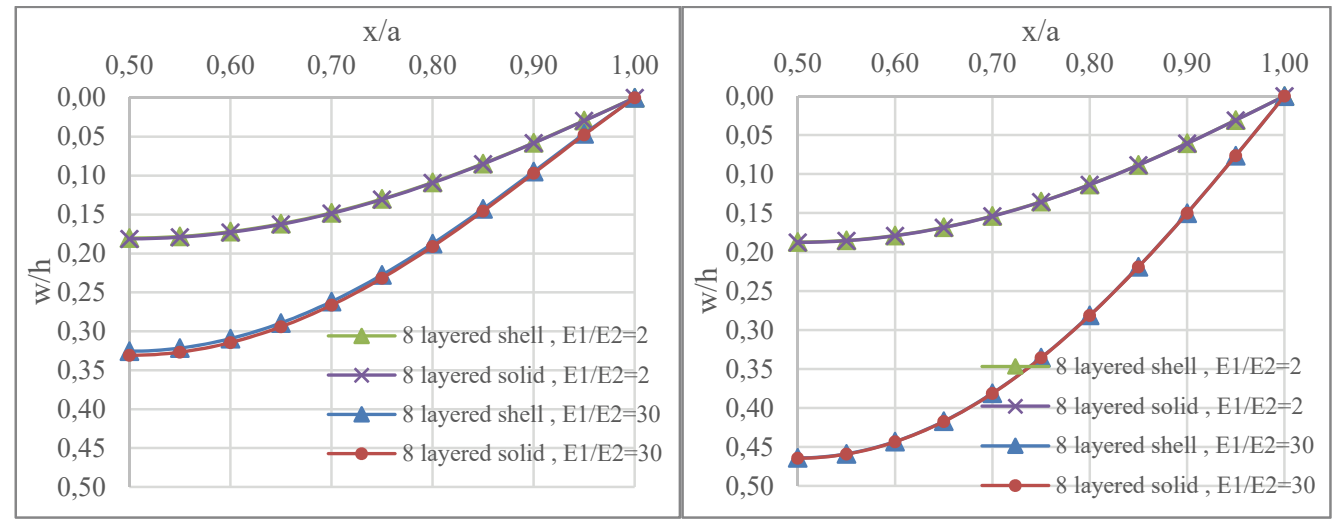

a)

b)

Figure 8-Comparison of dimensionless deflections using shell and 3D solid elements a) membrane effects are included b) membrane effects are excluded

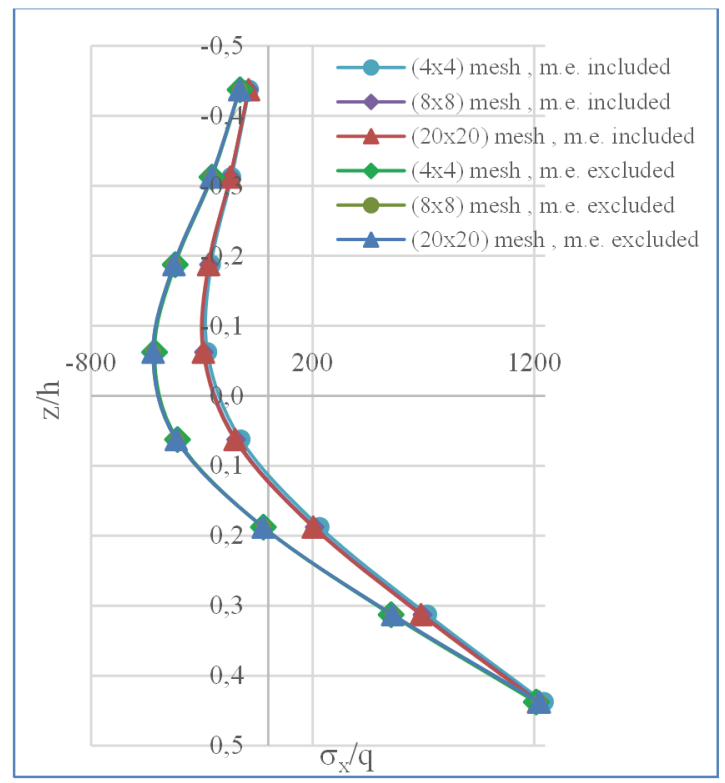

Figure 9 - Variation of dimensionless stresses with mesh refinement 
FE Analysis of FGM Plates on Arbitrarily Orthotropic Pasternak Foundations for ...

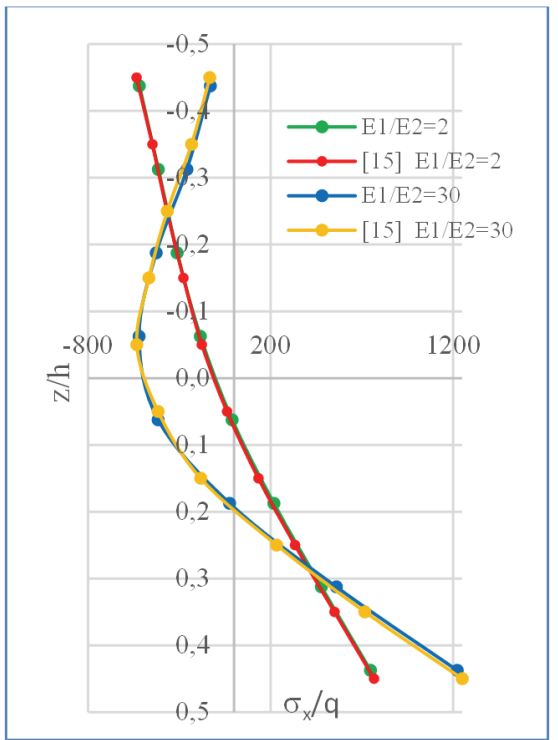

Figure 10- Comparison of dimensionless stresses (membrane effects are excluded)

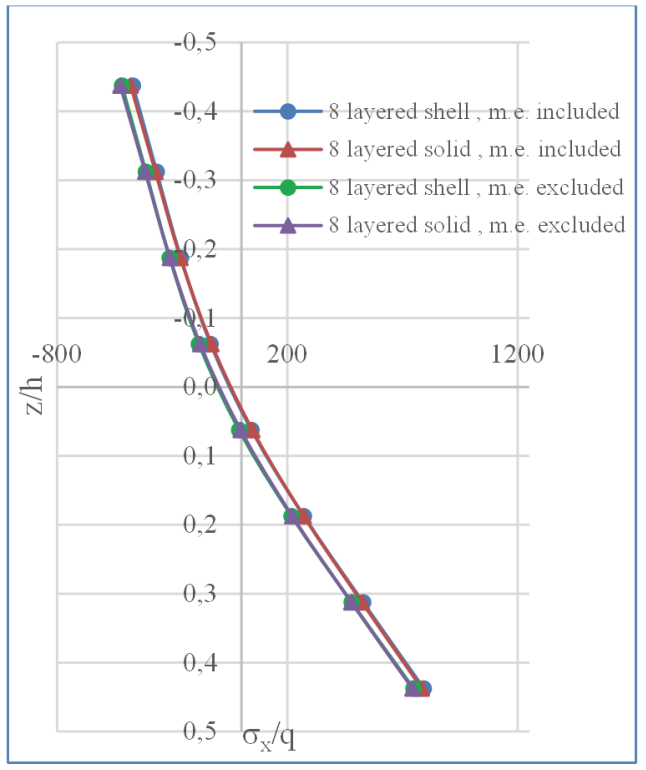

a)

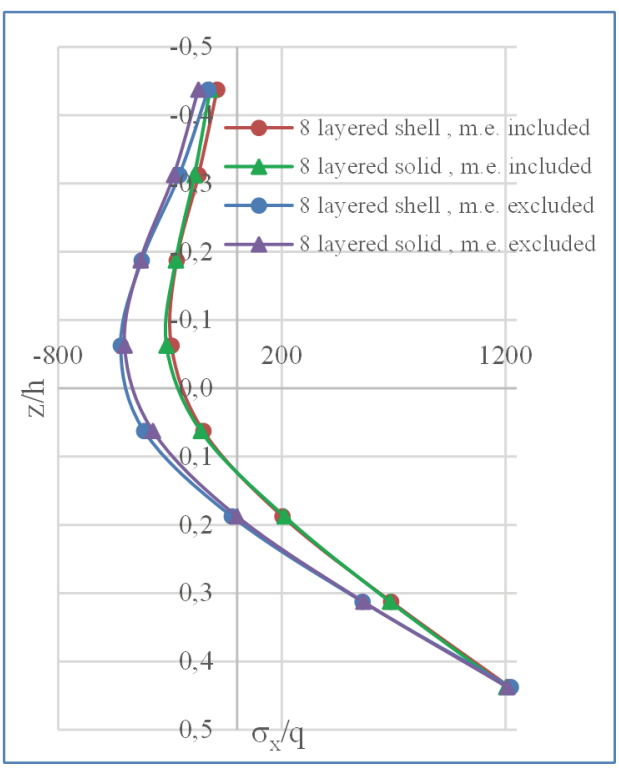

b)

Figure 11-Comparison of dimensionless stresses using layered shell and 3D solid finite elements a) $E_{1} / E_{2}=2$ b) $E_{1} / E_{2}=30$ 
A mesh refinement study using $(4 \times 4),(8 \times 8)$ and $(20 \times 20)$ meshes is also carried out for the dimensionless $\sigma_{\mathrm{x}}$ stress distributions through the thickness of the plate centre and results are given comparatively in Figure 9. Note that 8 layered shell finite elements are used in the models and the elastic modulus ratio is $\mathrm{E}_{1} / \mathrm{E}_{2}=30$. It is observed that all values match except for $(4 \times 4)$ mesh where a negligible difference occurs when membrane effects are included.

The dimensionless $\sigma_{\mathrm{x}}$ stress distributions through the thickness of the plate centre are obtained using a (20x20) mesh and 8 layered shell finite elements for different elastic modulus ratios and compared with the values given in [15]. It is observed that the results have very good agreement with the reference solution, as shown in Figure 10.

The dimensionless stress distributions are also verified with the results obtained using the 3D plate model for the cases with and without membrane effects. It is observed that the dimensionless stress values decrease with the inclusion of membrane effects and this decrement is more apparent when $\mathrm{E}_{1} / \mathrm{E}_{2}$ ratio increases. It is also seen that the neutral axis moves towards the mid-section of the plate when membrane effects are included, as in Figure 11.

\subsection{Homogeneous Plate on Isotropic Pasternak Foundation}

Static analysis of a rectangular plate resting on an isotropic Pasternak foundation subjected to a uniform loading and a central point load is performed and compared with the reference solutions given in $[21,22]$ to verify the proposed plate-foundation model. The geometrical and loading properties of the plate-foundation system are shown in Figure 12.
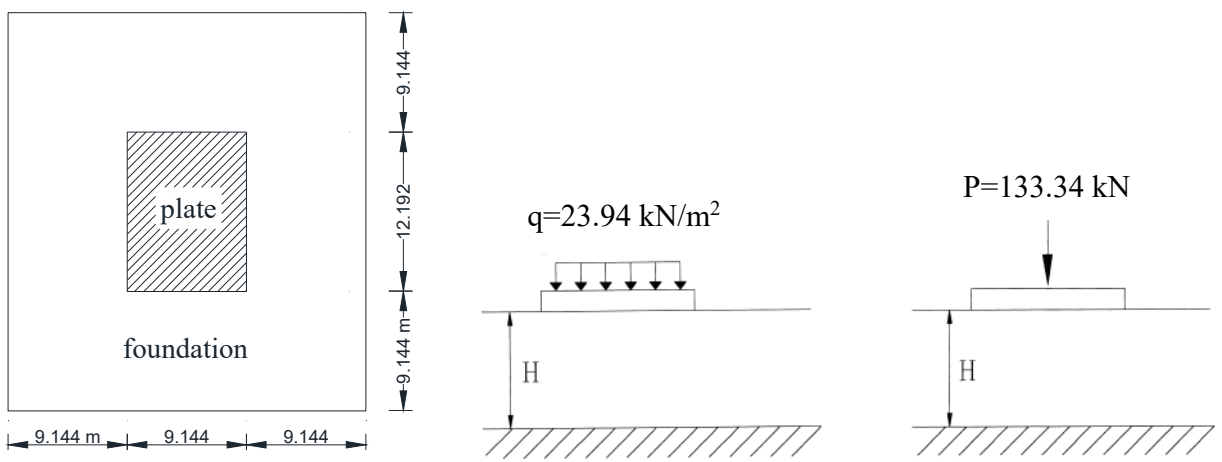

Figure 12 - Plan and vertical section of plate-foundation system

The plate thickness is $\mathrm{h}=0.1524 \mathrm{~m}$ and the material properties of the plate are; $\mathrm{E}=2.0685 \times 10^{6} \mathrm{kN} / \mathrm{m}^{2}$ and $v=0.2$. The foundation is extended in the in-plane directions and the plate rests freely on the foundation without assigning any boundary conditions to the edges. Here, the plate is modelled using thin plate finite elements.

The four-noded plate finite element used for modelling homogeneous plates has 3 degrees of freedom at each node, one translational degree of freedom in the direction normal to the plane of the element and 2 out-of-plane rotational degrees of freedom. In the thick plate 
finite element formulation, the effects of transverse shear deformation are included whereas in the thin plate finite element formulation, transverse shearing deformation is neglected.

The midpoint deflections of the plate under uniformly distributed loading and under central point load for different soil depths are given in Table 1 and Table 2, respectively. Here, $\mathrm{k}_{\mathrm{w}}$ is the first parameter (the coefficient of subgrade reaction), $\mathrm{k}_{\mathrm{p}}$ is the second parameter (the shear modulus) of the Pasternak foundation.

The results are in good agreement with the reference solutions indicating that the proposed model fully represents the expected behaviour of the isotropic plate-foundation system.

Table 1 - Midpoint deflections of the plate under uniformly distributed loading for different soil depths

\begin{tabular}{|c|c|c|c|c|c|}
\hline \multicolumn{2}{|c|}{$\mathrm{H}(\mathrm{m})$} & 3.048 & 6.096 & 9.144 & 15.24 \\
\hline \multicolumn{2}{|c|}{$\mathrm{k}_{\mathrm{w}}\left(\mathrm{kN} / \mathrm{m}^{3}\right)$} & 27206.59 & 13757.63 & 9377.96 & 5964.21 \\
\hline \multicolumn{2}{|c|}{$\mathrm{k}_{\mathrm{p}}\left(\mathrm{kN} / \mathrm{m}^{2}\right)$} & 26905.91 & 50410.87 & 70586.50 & 104664.46 \\
\hline \multirow{2}{*}{$\mathrm{w} \mathrm{x10-2}(\mathrm{m})$} & Ref.[22] & 0.08720 & 0.15260 & 0.18930 & 0.22120 \\
\cline { 2 - 6 } & Ref.[21] & 0.08530 & 0.15240 & 0.18900 & 0.20700 \\
\cline { 2 - 6 } & $\begin{array}{c}\text { Present } \\
\text { study }\end{array}$ & 0.08713 & 0.15300 & 0.18900 & 0.22100 \\
\hline
\end{tabular}

Table 2 - Midpoint deflections of the plate under central point load for different soil depths

\begin{tabular}{|c|c|c|c|c|c|}
\hline \multicolumn{2}{|l|}{$\mathrm{H}(\mathrm{m})$} & 3.048 & 6.096 & 9.144 & 15.24 \\
\hline \multicolumn{2}{|c|}{$\mathrm{k}_{\mathrm{w}}\left(\mathrm{kN} / \mathrm{m}^{3}\right)$} & 31898.08 & 24256.05 & 23737.98 & 23710.59 \\
\hline \multicolumn{2}{|c|}{$\mathrm{k}_{\mathrm{p}}\left(\mathrm{kN} / \mathrm{m}^{2}\right)$} & 18913.08 & 23597.82 & 24035.56 & 24060.66 \\
\hline \multirow{3}{*}{$\mathrm{W} \times 10^{-2}(\mathrm{~m})$} & Ref.[22] & 0.08180 & 0.08450 & 0.08460 & 0.08460 \\
\hline & Ref.[21] & 0.04800 & 0.09750 & 0.09750 & 0.09750 \\
\hline & $\begin{array}{c}\text { Present } \\
\text { study }\end{array}$ & 0.07617 & 0.08052 & 0.08076 & 0.08077 \\
\hline
\end{tabular}

\subsection{Simply Supported Homogeneous Plate on Isotropic Pasternak Foundation}

\section{Example 1:}

A simply supported homogeneous square plate resting on an isotropic Pasternak foundation given in $[28,46]$ is modelled using thin plate finite elements and solved for different soil parameters. The plate is subjected to a uniformly distributed load of $\mathrm{q}=\mathrm{E} / 10^{5} \mathrm{kN} / \mathrm{m}^{2}$. Length to height ratio of the plate is $\mathrm{a} / \mathrm{h}=100$ and the Poisson's ratio is $\mathrm{v}=0.3$.

Dimensionless central deflections are obtained and compared with the reference solutions as given in Table 3. Here, the dimensionless central deflection is defined as $\mathrm{w}^{\prime}=10^{3} \mathrm{D} \mathrm{w} /$ $\mathrm{qa}^{4}$ where $D=\frac{E h^{3}}{12\left(1-v^{2}\right)}, \mathrm{K}_{\mathrm{w}}$ and $\mathrm{K}_{\mathrm{p}}$ are the soil parameters in non-dimensional form 
expressed as $K_{w}=k_{w} a^{4} / D$ and $K_{p}=k_{p} a^{2} / D$. Results obtained in this study are very close to the reference values, and it is observed that the deflections decrease with increasing shear modulus as expected.

Table 3 - Dimensionless central deflections of a uniformly loaded square plate on Pasternak foundation

\begin{tabular}{|c|c|c|c|c|}
\hline \multirow{2}{*}{$\mathrm{K}_{\mathrm{w}}$} & \multirow{2}{*}{$\mathrm{K}_{\mathrm{p}}$} & \multicolumn{3}{|c|}{ Dimensionless central deflection } \\
\cline { 3 - 5 } & & present & Ref. [28] & Ref. [46] \\
\hline 1 & 1 & 3.8536 & 3.8546 & 3.8530 \\
\hline 1 & 81 & 0.7690 & 0.7630 & 0.7630 \\
\hline 1 & 625 & 0.1162 & 0.1153 & 0.1150 \\
\hline
\end{tabular}

\section{Example 2:}

A simply supported homogeneous square plate resting on two different foundation types, Winkler and isotropic Pasternak foundations, is modelled using thick plate finite elements and the deflection and moment values obtained at the plate centre are compared with those given in [24]. The plate is subjected to a uniformly distributed load of $\mathrm{q}=30 \mathrm{kN} / \mathrm{m}^{2}$. Plate length is $\mathrm{a}=10 \mathrm{~m}$ and the thickness is $\mathrm{h}=0.5 \mathrm{~m}$. elastic modulus and Poisson's ratio are $\mathrm{E}=200 \times 10^{6} \mathrm{kN} / \mathrm{m}^{2}$ and $v=0.167$, respectively. The coefficient of subgrade reaction is $\mathrm{k}_{\mathrm{w}}=5620 \mathrm{kN} / \mathrm{m}^{3}$ and the shear modulus of the Pasternak foundation is $\mathrm{k}_{\mathrm{p}}=120000 \mathrm{kN} / \mathrm{m}^{2}$. Note that the shear moduli of the soil element are assigned to zero values to represent the Winkler foundation.

The results given in Table 4 show that the central deflection and moment values obtained in this study are very close to the reference values where the relative errors are between $2.5-3$ $\%$.

Table 4 - Central deflections and moments of a uniformly loaded square plate on Winkler and Pasternak foundations

\begin{tabular}{|c|c|c|c|c|}
\hline & \multicolumn{2}{|c|}{ Winkler } & \multicolumn{2}{c|}{ Pasternak } \\
\hline & Ref.[24] & $\begin{array}{c}\text { Present } \\
\text { study }\end{array}$ & Ref.[24] & $\begin{array}{c}\text { Present } \\
\text { study }\end{array}$ \\
\hline $\mathrm{W} \times 10^{4}(\mathrm{~m})$ & 5.329 & 5.498 & 4.187 & 4.298 \\
\hline $\mathrm{M}(\mathrm{kNm} / \mathrm{m})$ & 120.250 & 124.125 & 92.730 & 95.281 \\
\hline
\end{tabular}

\subsection{Simply Supported Homogeneous Plate on Orthotropic Pasternak Foundation}

The dimensionless angular frequencies of the first 5 modes of a square homogeneous plate resting on an orthotropic foundation with different material angles are obtained and compared with the solution given by Kutlu [37] to verify the orthotropic foundation model. 
The plate is modelled using thick plate finite elements. Material and geometrical properties of the homogeneous plate are $\mathrm{E}=25 \times 10^{6} \mathrm{kN} / \mathrm{m}^{2}, v=0.3, \mathrm{a}=10 \mathrm{~m}$ and $\mathrm{h}=1 \mathrm{~m}$. The dimensionless coefficient of subgrade reaction and shear moduli are $K_{w}=100, K_{p x}=10$ and $\mathrm{K}_{\mathrm{py}}=70$, respectively.

The coefficient of subgrade reaction of the soil is $\mathrm{k}_{\mathrm{w}}=22893.773 \mathrm{kN} / \mathrm{m}^{3}$ and shear moduli of the soil are $\mathrm{k}_{\mathrm{px}}=228937.73 \mathrm{kN} / \mathrm{m}^{2}$ and $\mathrm{k}_{\mathrm{py}}=1602564.1 \mathrm{kN} / \mathrm{m}^{2}$. Dimensionless angular frequencies are calculated using $\omega^{\prime}=\frac{\omega a^{2}}{\pi^{2}} \sqrt{\frac{\rho h}{D}}$ where $\rho=2550 \mathrm{~kg} / \mathrm{m}^{3}$.

The dimensionless angular frequencies of the system obtained for 7 different material angles are given comparatively in Table 5. It is seen that the values are very close to each other which verifies the orthotropic Pasternak foundation model. Note that the dimensionless angular frequency values are the same for complementary angles due to the symmetry of the system in both geometry and loading.

Table 5 - Dimensionless angular frequencies of the first 5 modes for different material angles

\begin{tabular}{|c|c|c|c|c|c|c|c|c|}
\hline & & $\theta=0^{\circ}$ & $\theta=15^{\circ}$ & $\theta=30^{\circ}$ & $\theta=45^{\circ}$ & $\theta=60^{\circ}$ & $\theta=75^{\circ}$ & $\theta=90^{\circ}$ \\
\hline \multirow[b]{2}{*}{ mode 1} & Ref.[37] & 3.5716 & 3.5616 & 3.5413 & 3.5310 & 3.5413 & 3.5616 & 3.5716 \\
\hline & $\begin{array}{l}\text { Present } \\
\text { study }\end{array}$ & 3.5371 & 3.5276 & 3.5082 & 3.4984 & 3.5082 & 3.5276 & 3.5371 \\
\hline \multirow[b]{2}{*}{ mode 2} & Ref.[37] & 5.7530 & 5.8207 & 5.9895 & 6.1075 & 5.9895 & 5.8207 & 5.7530 \\
\hline & $\begin{array}{l}\text { Present } \\
\text { study }\end{array}$ & 5.6807 & 5.7510 & 5.9266 & 6.0514 & 5.9266 & 5.7510 & 5.6807 \\
\hline \multirow[b]{2}{*}{ mode 3} & Ref.[37] & 7.1451 & 7.0716 & 6.8915 & 6.7678 & 6.8915 & 7.0716 & 7.1451 \\
\hline & $\begin{array}{l}\text { Present } \\
\text { study }\end{array}$ & 7.0546 & 6.9811 & 6.7995 & 6.6716 & 6.7995 & 6.9811 & 7.0546 \\
\hline \multirow[b]{2}{*}{ mode 4} & [Ref.37] & 9.0773 & 8.9905 & 8.8897 & 8.8529 & 8.8897 & 8.9905 & 9.0773 \\
\hline & $\begin{array}{l}\text { Present } \\
\text { study }\end{array}$ & 8.7947 & 8.7332 & 8.6499 & 8.6178 & 8.6499 & 8.7332 & 8.7947 \\
\hline \multirow[b]{2}{*}{ mode 5} & Ref.[37] & 9.5259 & 9.7388 & 10.1921 & 10.6600 & 10.1921 & 9.7388 & 9.5259 \\
\hline & $\begin{array}{l}\text { Present } \\
\text { study }\end{array}$ & 9.4438 & 9.6309 & 10.0631 & 10.5428 & 10.0631 & 9.6309 & 9.4438 \\
\hline
\end{tabular}

\section{SIMPLY SUPPORTED S-FGM PLATE ON ORTHOTROPIC PASTERNAK FOUNDATION}

The finite element analysis of a simply supported S-FGM square plate resting on an orthotropic Pasternak foundation is performed next, using layered shell finite elements. The elastic modulus at the bottom surface of the plate is $\mathrm{E}_{1}=25 \times 10^{6} \mathrm{kN} / \mathrm{m}^{2}$, the Poisson's ratio is $v=0.3$, the thickness is $\mathrm{h}=1 \mathrm{~m}$ and the length is $\mathrm{a}=10 \mathrm{~m}$. The plate is subjected to a uniformly distributed load of $\mathrm{q}=100 \mathrm{kN} / \mathrm{m}^{2}$. The dimensionless coefficient of subgrade 
reaction and shear moduli are $\mathrm{K}_{\mathrm{w}}=100, \mathrm{~K}_{\mathrm{px}}=10$ and $\mathrm{K}_{\mathrm{py}}=70$, respectively where the material angle is $0^{\circ}$.

The deflections of the S-FGM plate along the $\mathrm{x}$ direction (at $\mathrm{y}=5 \mathrm{~m}$ ) for the cases with and without membrane effects are obtained for $E_{1} / E_{2}=2$ and $E_{1} / E_{2}=30$. The plate is modelled with 2 and 8 layers in order to observe the effect of the number of layers used defining the variation of the elastic modulus of the S-FGM plate on deflections and it is seen that for all cases, the deflection values do not change with the number of layers used, Figures 13-14.

Comparison of the deflections according to the inclusion and exclusion of membrane effects is given in Figure 15 and it is observed that the deflection difference becomes more apparent as the elastic modulus ratio increases or in other words, as the elastic modulus decreases with a larger ratio from the bottom to the top surface of the plate.

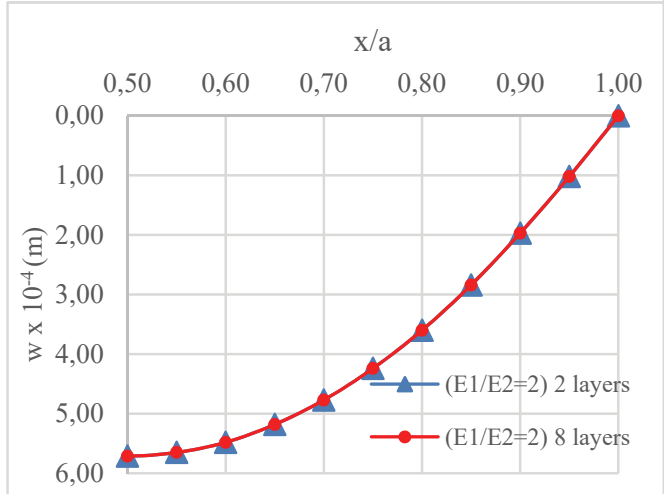

a)

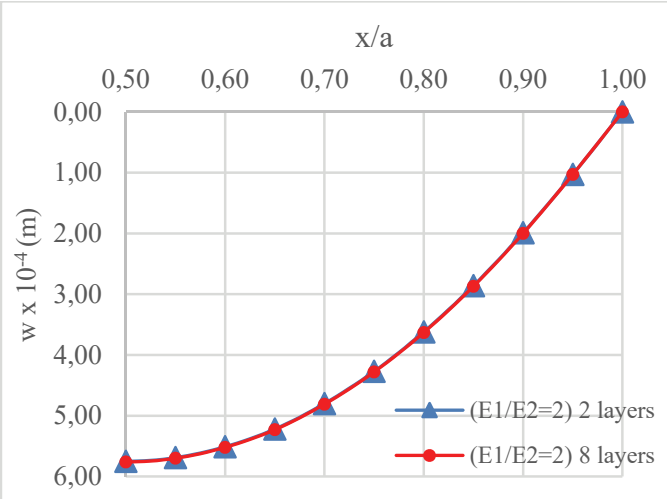

b)

Figure 13 - Comparison of deflections for different number of layers $\left(E_{1} / E_{2}=2\right)$
a) membrane effects are included
b) membrane effects are excluded

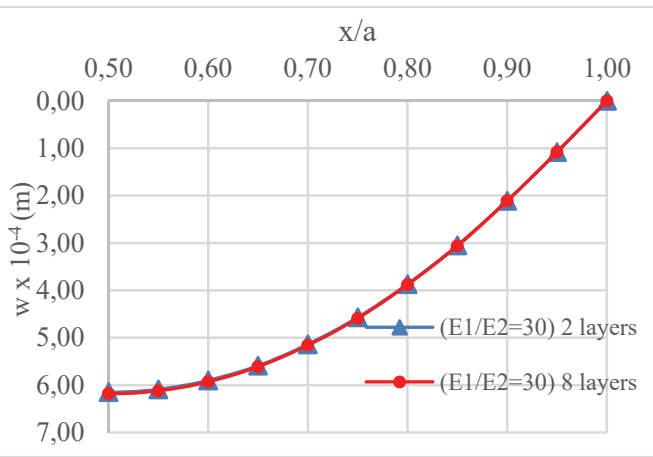

a)

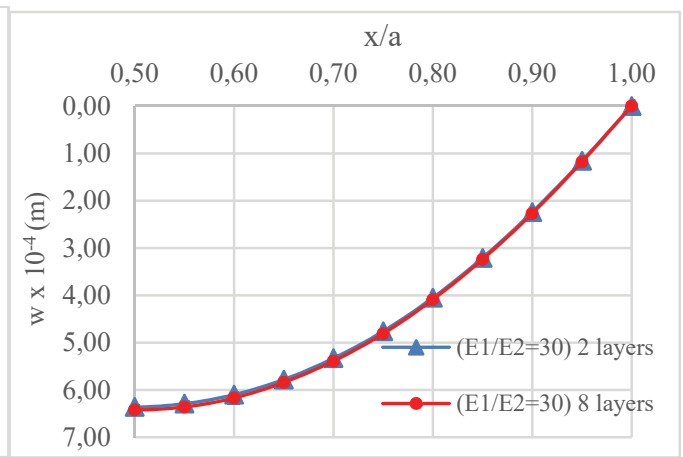

b)

Figure 14 - Comparison of deflections for different number of layers $\left(E_{1} / E_{2}=30\right)$ $\begin{array}{lll}\text { a) membrane effects are included } & \text { b) membrane effects are excluded }\end{array}$ 


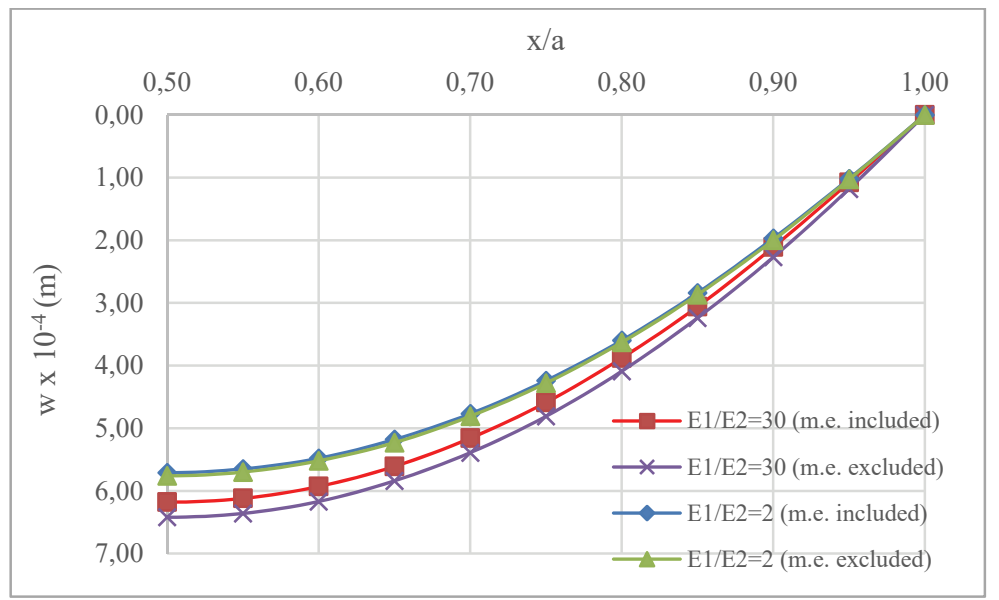

Figure 15 - Comparison of deflections using 8 layers

The stress distributions through the thickness of the plate centre are investigated according to the elastic modulus ratio and membrane effects using two layers, Figure 16. $\sigma_{\mathrm{x}}$ and $\sigma_{\mathrm{y}}$ stresses are analogous but their magnitudes differ from each other due to the orthotropic property of the soil material. The stress distributions for $E_{1} / E_{2}=1$ corresponding to a homogeneous plate material are linear and the graphs for $\sigma_{\mathrm{x}}$ and $\sigma_{\mathrm{y}}$ gradually turn into curved shapes towards the top surface, as $E_{1} / E_{2}$ ratio increases. Besides, stress distributions diverge from each other for the cases with and without membrane effects as $E_{1} / E_{2}$ ratio increases. Note that the stress values are obtained at the top and bottom levels of each layer to be able to capture 3 stress values for the 2 layered solution.

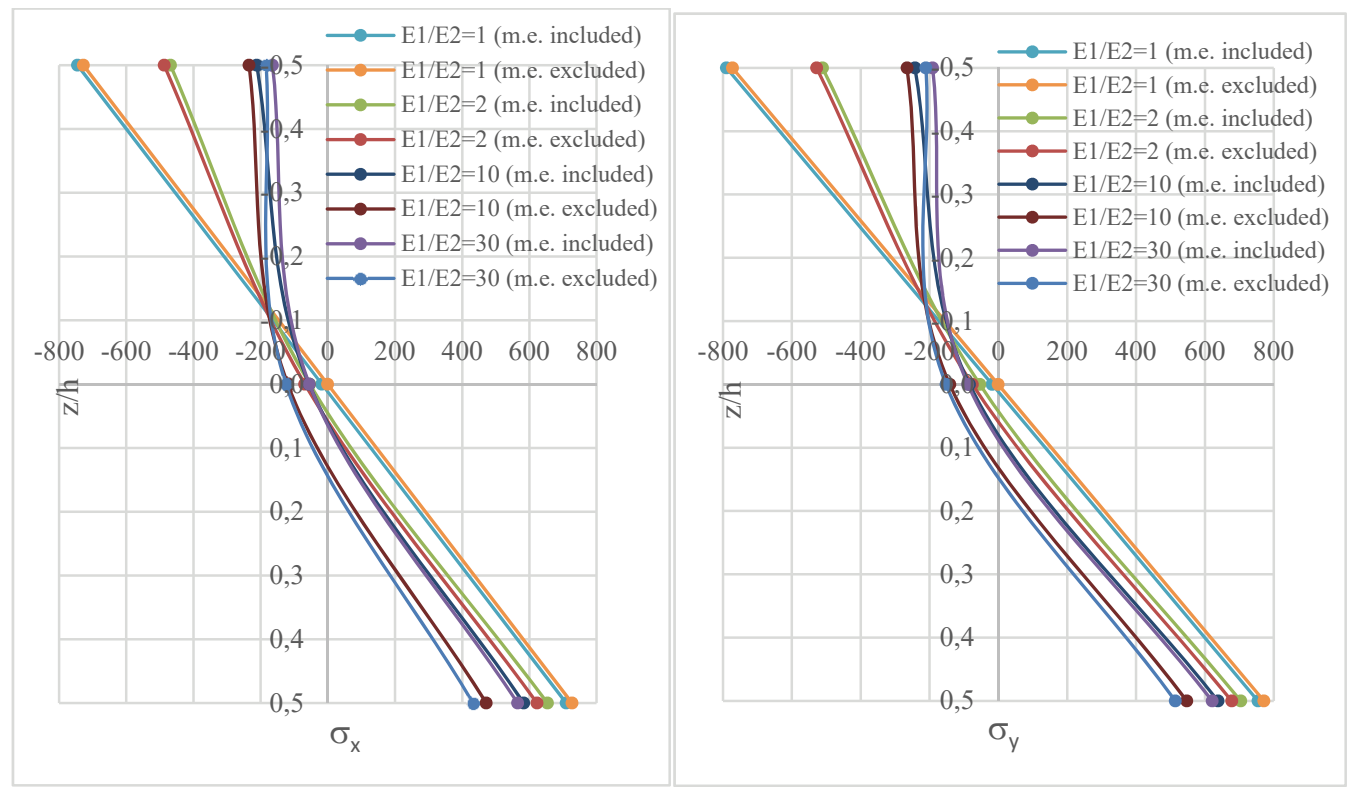

Figure $16-\sigma_{x}$ and $\sigma_{y}$ stress distributions for different $E_{1} / E_{2}$ ratios 
Then, the stress distributions are recalculated for different number of layers used in modelling the S-FGM plate and shown comparatively in Figure 17. $\sigma_{\mathrm{x}}$ and $\sigma_{\mathrm{y}}$ stresses obtained for 4 and 8 layers are almost the same while they differ slightly near the top and bottom surfaces when 2 layers are used.

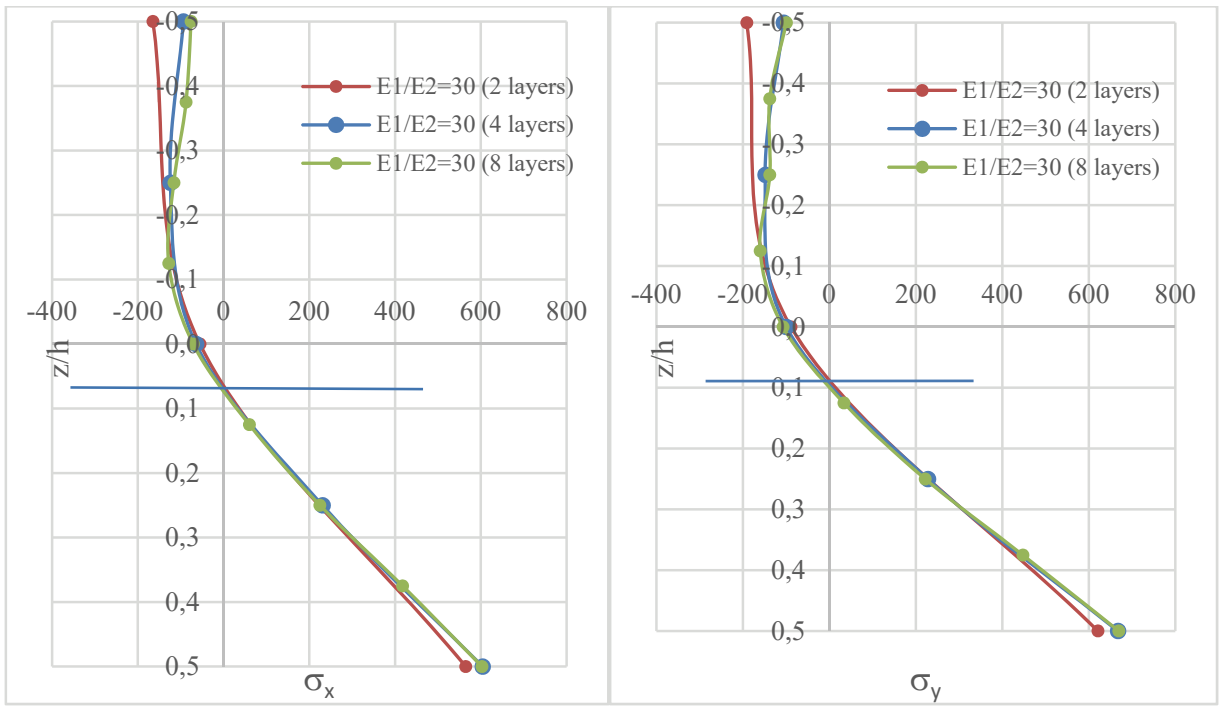

Figure $17-\sigma_{x}$ and $\sigma_{y}$ stress distributions for different number of layers (membrane effects are included)

In addition, two alternate arrangements of the S-FGM plate on the orthotropic Pasternak foundation are considered and solved for the stresses through the thickness of the plate for comparison. The $\sigma_{x}$ and $\sigma_{y}$ stress components in Figures 18a-19a belong to the arrangement where the surface with larger elastic modulus is attached to the elastic foundation whereas Figures $18 \mathrm{~b}-19 \mathrm{~b}$ indicate the stress distributions of the plate in the reverse arrangement. It is observed that $\sigma_{\mathrm{x}}$ and $\sigma_{\mathrm{y}}$ stresses start diverging towards the top surface as the elastic modulus decreases rapidly and this situation is the reverse for the other case, Figures 18-19. It is also obtained that zero $\sigma_{\mathrm{x}}$ and $\sigma_{\mathrm{y}}$ stresses which are at the mid-section of the homogeneous plate, are below and above the mid-section for the two arrangements, respectively due to the heterogeneity of the material.

$\sigma_{\mathrm{x}}$ and $\sigma_{\mathrm{y}}$ stress components are obtained for different material angles ranging from $0^{\circ}$ to $90^{\circ}$ at intervals of $15^{\circ}$ and given comparatively in Figure 20. The elastic modulus ratio of the S-FGM plate is taken as $E_{1} / E_{2}=30$ and the system is analysed for the case where membrane effects are included. $\sigma_{\mathrm{x}}$ and $\sigma_{\mathrm{y}}$ stresses have the maximum divergence at the bottom surface and after converging, they reach the top surface almost with a constant difference.

Finally, the midpoint deflections are investigated for three different cases in which the nondimensional soil parameters are; $\mathrm{K}_{\mathrm{w}}=100 \quad \mathrm{~K}_{\mathrm{px}}=10 \quad \mathrm{~K}_{\mathrm{py}}=70$ (case 1); $\mathrm{K}_{\mathrm{w}}=100 \quad \mathrm{~K}_{\mathrm{px}}=10$ $\mathrm{K}_{\mathrm{py}}=140$ (case 2) ; $\mathrm{K}_{\mathrm{w}}=100 \quad \mathrm{~K}_{\mathrm{px}}=10 \quad \mathrm{~K}_{\mathrm{py}}=280$ (case 3). Coefficient of subgrade reaction and one of the shear moduli of the foundation are kept constant while the other shear modulus is doubled in each case. 


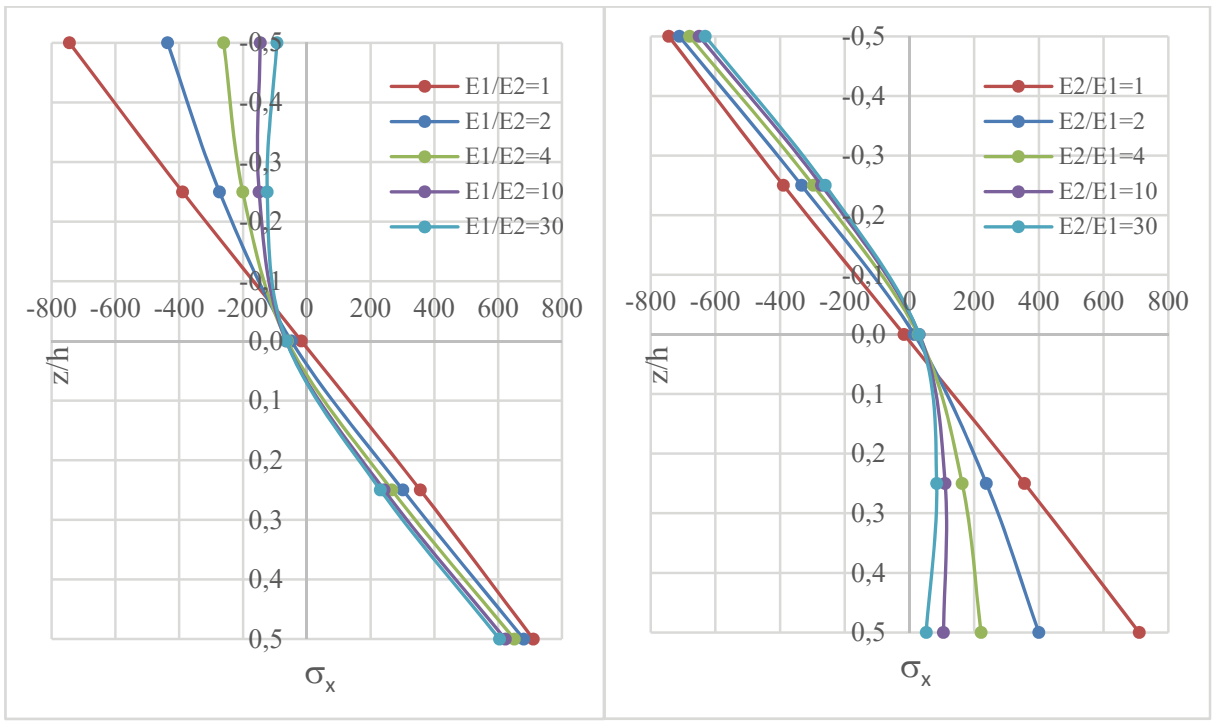

Figure 18 - $\sigma_{x}$ stress distributions for different $E_{1} / E_{2}$ and $E_{2} / E_{1}$ ratios (membrane effects are included)

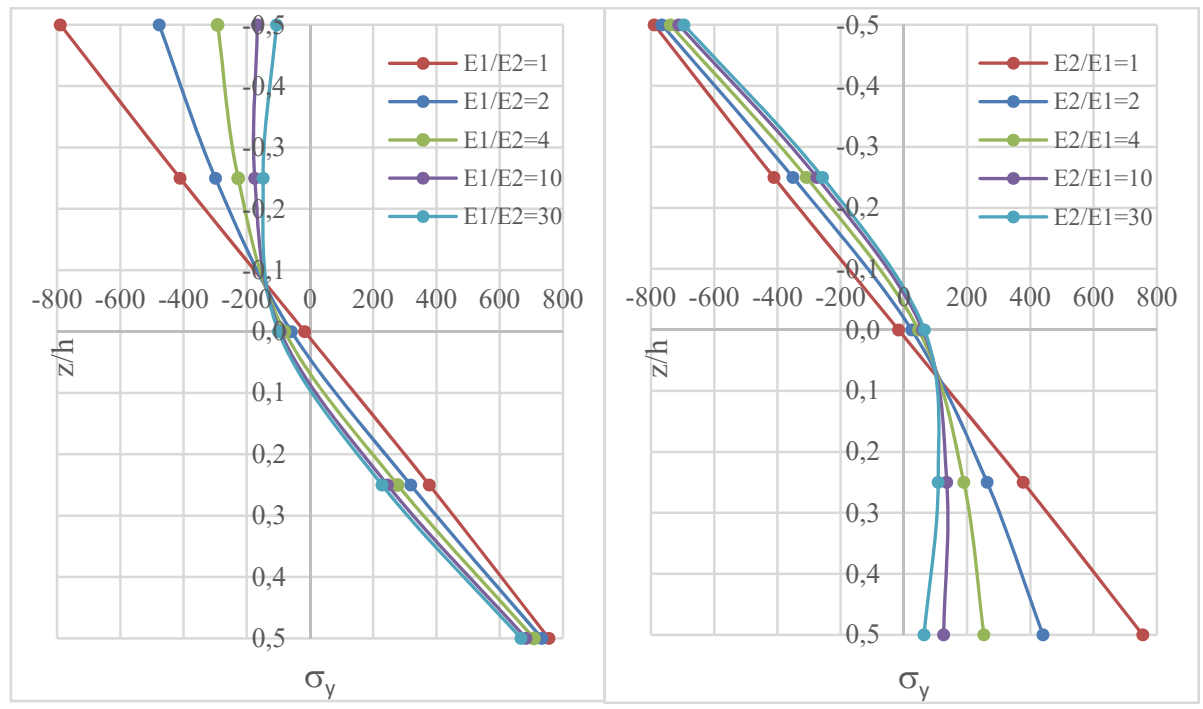

Figure $19-\sigma_{y}$ stress distributions for different $E_{1} / E_{2}$ and $E_{2} / E_{1}$ ratios (membrane effects are included)

Two different elastic modulus ratios for the plate and seven material angles for the foundation are considered for all cases. It is observed in Figure 21 that the midpoint 
deflections decrease with increasing shear modulus. The maximum midpoint deflection value is achieved when the material angle is $45^{\circ}$ and the remaining values are in descending order and are the same for complementary angles. Besides, the midpoint deflections for $E_{1} / E_{2}=30$ are larger than the values obtained for $E_{1} / E_{2}=2$. In other words, midpoint deflections increase for "softer" top surfaces. This increment becomes more apparent when the membrane effects are excluded and with decreasing shear modulus, Figures 21-22.

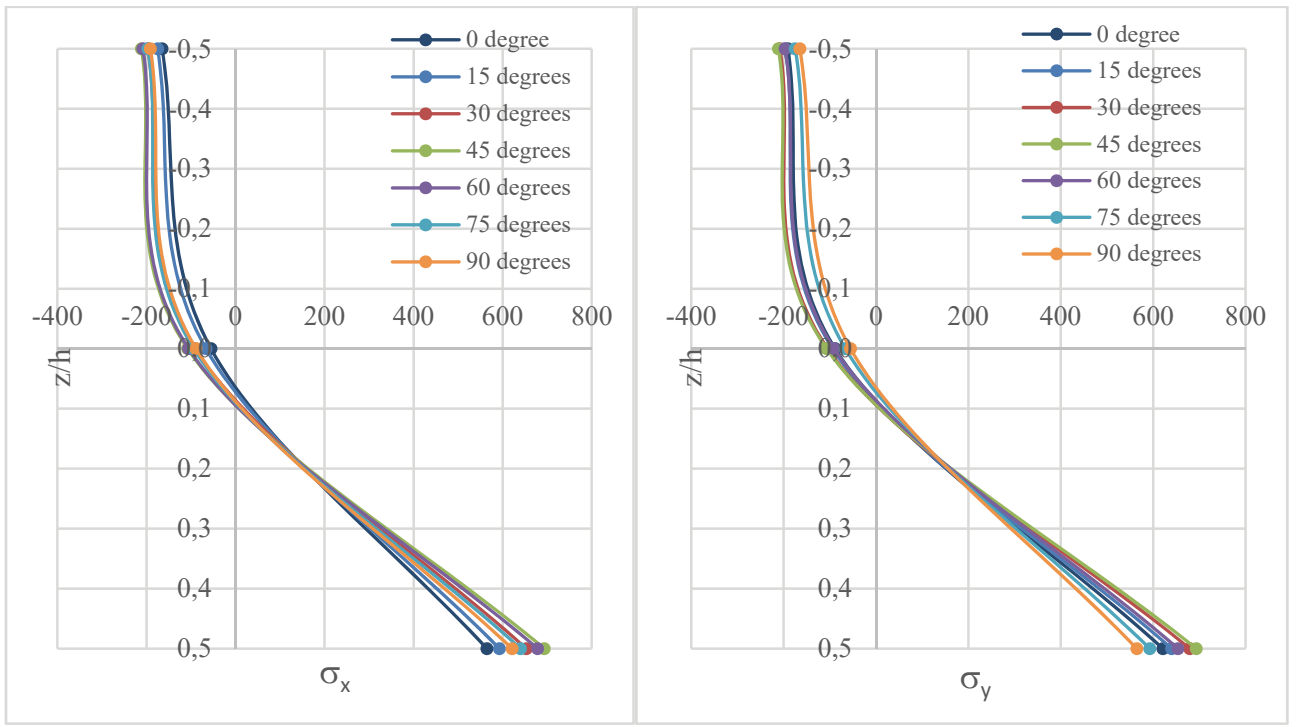

Figure $20-\sigma_{x}$ and $\sigma_{y}$ stress distributions for different material angles $\left(E_{1} / E_{2}=30\right.$, membrane effects are included)

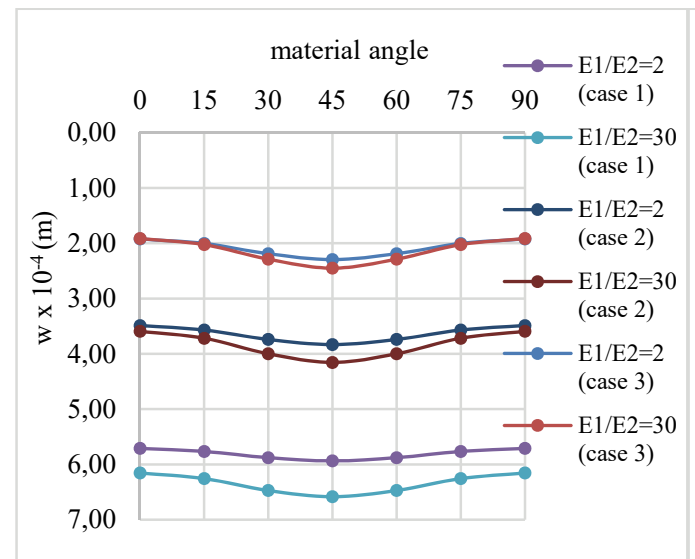

a)

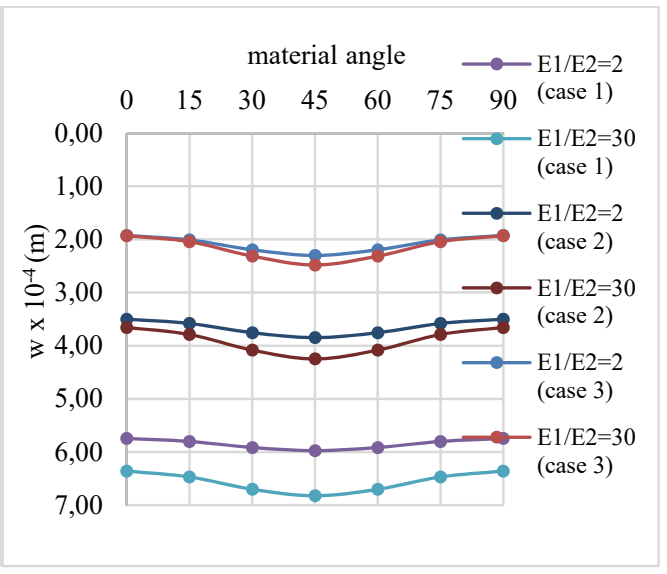

b)

Figure 21 - Mid-point deflections for different material angles a) membrane effects are included b) membrane effects are excluded 


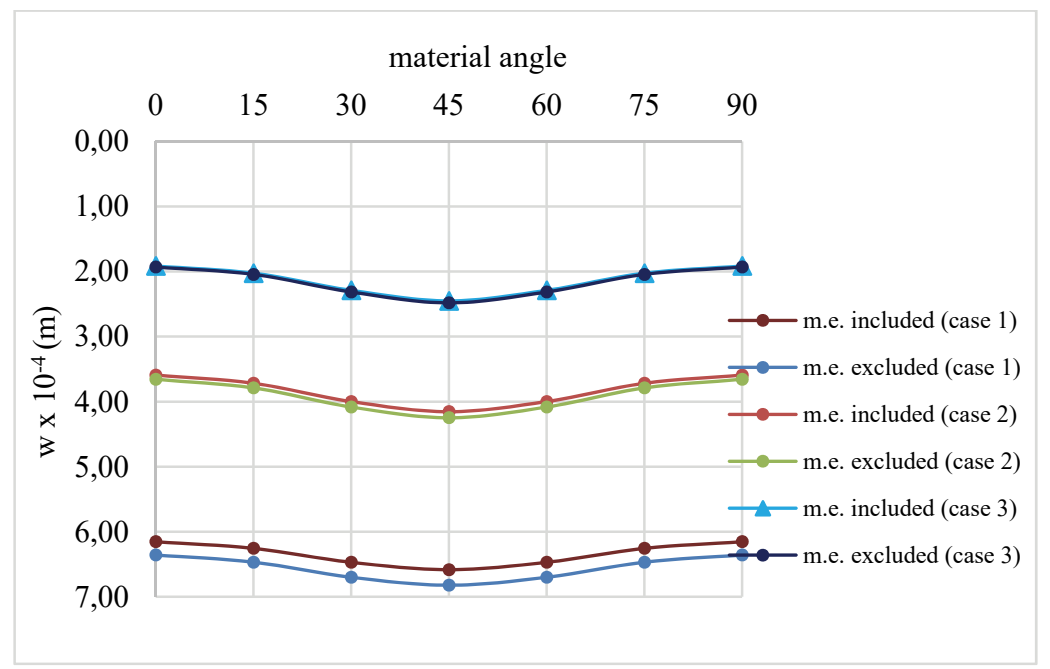

Figure 22 - Mid-point deflections for different material angles $\left(E_{1} / E_{2}=30\right)$

\section{CONCLUSIONS}

In this study, the finite element analysis of S-FGM plates with and without membrane effects, resting on orthotropic Pasternak elastic foundations with different material angles is carried out using SAP2000 software package. It is demonstrated with the verification examples that the proposed model is convenient and robust. This work can be easily extended to static and dynamic analyses of FGM plates with various geometries resting on arbitrarily orthotropic Pasternak foundations for further studies.

The results obtained in the present study can be summarised as follows:

1) For small elastic modulus ratios (e.g. $E_{1} / E_{2}=2$ ), the deflections of the S-FGM plate both with and without Pasternak foundation do not change with the number of layers used for the plate.

2) For large elastic modulus ratios (e.g. $E_{1} / E_{2}=30$ ), the deflections of the plate on Pasternak foundation do not change with the number of layers used whereas the deflections of the plate without Pasternak foundation increase at a lower rate as the number of layers increases.

3) The deflections increase when the membrane effects are excluded and the deflection difference between the cases with and without membrane effects becomes more apparent as the elastic modulus decreases with a larger ratio from the bottom to the top surface of the plate.

4) Stresses $\sigma_{x}$ and $\sigma_{y}$ through the thickness of the plate centre are analogous but their magnitudes differ from each other due to the orthotropic property of the soil material. All stress distributions for a homogeneous plate material are linear while the distributions for $\sigma_{\mathrm{x}}$ and $\sigma_{\mathrm{y}}$ gradually turn into curved shapes towards the top surface as $\mathrm{E}_{1} / \mathrm{E}_{2}$ ratio increases. 
5) The stress distributions diverge for the cases with and without membrane effects as $\mathrm{E}_{1} / \mathrm{E}_{2}$ ratio increases.

6) Stresses $\sigma_{x}$ and $\sigma_{y}$ obtained for 4 and 8 layers are almost the same while they differ slightly near the top and bottom surfaces when 2 layers are used.

7) Stresses $\sigma_{\mathrm{x}}$ and $\sigma_{\mathrm{y}}$ start diverging towards the top surface as the elastic modulus decreases with a larger rate for the arrangement of the S-FGM plate where the surface with larger elastic modulus is attached to the orthotropic Pasternak foundation. This divergence is towards the bottom surface for the opposite positioning of the plate. Zero $\sigma_{x}$ and $\sigma_{y}$ stresses which are at the mid-section of the homogeneous plate, are below and above the mid-section for the two arrangements, respectively due to the heterogeneity of the material.

8) For different material angles, $\sigma_{x}$ and $\sigma_{y}$ stresses have the maximum divergence at the bottom surface and after converging, they reach the top surface almost with a constant difference.

9) The midpoint deflections decrease with increasing shear modulus of the foundation. The maximum midpoint deflection value is achieved when the material angle is $45^{\circ}$ and the remaining values are in descending order and are the same for complementary angles.

10) The midpoint deflections increase for softer top surfaces and this increment becomes more apparent with decreasing shear modulus and when the membrane effects are excluded.

\section{Acknowledgements}

Engin Orakdöğen and Kutlu Darılmaz are gratefully acknowledged for their fruitful suggestions on this study.

\section{References}

[1] Suresh S., Mortenson A., Fundamentals of Functionally Graded Materials: Processing and Thermomechanical Behavior of Graded Metals and Metal-Ceramic Composites. IOM Communications Ltd, London, UK, 1998.

[2] Koizumi M., FGM activities in Japan. Composites Part B: Eng 28(1-2), 1-4, 1997.

[3] Tanigawa Y., Some basic thermoelastic problems for nonhomogeneous structural materials. Appl. Mech. Rev. 48(6), 287-300, 1995.

[4] Suresh S., Mortensen A., Functionally graded metals and metalceramic composites 2: thermomechanical behaviour. Int. Mater. Rev. 42(3), 85-116, 1997.

[5] Reddy J.N., Analysis of functionally graded plates. Int. J. Numer. Methods Eng., 47, 663-684, 2000.

[6] Cheng Z.Q., Batra R.C. Deflection relationships between the homogenous Kirchhoff plate theory and different functionally graded plate theories. Archives of Mechanics $52,143-158,2000$. 
[7] Bao G., Wang L., Multiple cracking in functionally graded ceramic/metal coatings. Int. J. Solids Struct., 32, 2853-2871, 1995.

[8] Jin Z.H., Paulino G.H., Transient thermal stress analysis of an edge crack in a functionally graded material. Int. J. Fracture, 107, 73-98, 2001.

[9] Delale F., Erdogan F., The crack problem for a nonhomogeneous plane. ASME J. Appl. Mech., 50, 609-614,1983.

[10] Erdogan F., Wu B.H., Crack problems in FGM layers under thermal stresses. J. Therm. Stress., 19, 237-265, 1996.

[11] Chung Y.L., Chi S.H., The residual stress of functionally graded materials. J. Chin. Inst. Civ. Hydraul. Eng., 13, 1-9, 2001.

[12] Chi S.H., Chung Y.L., Cracking in sigmoid functionally graded coating. J. Mech., 18, 41-53, 2002.

[13] Chi S.H., Chung Y.L., Mechanical behavior of functionally graded material plates under transverse load-Part I: Analysis. Int. J. of Solids and Str., 43, 3657-3674, 2006a.

[14] Chi S.H., Chung Y.L., Mechanical behavior of functionally graded material plates under transverse load-Part II: Numerical results. Int. J. of Solids and Str., 43, 36753691, 2006b.

[15] Orakdöğen E., Küçükarslan S., Sofiyev A., Omurtag M.H., Finite element analysis of functionally graded plates for coupling effect of extension and bending. Meccanica, 45, 63-72, 2010.

[16] Zenkour A.M., Generalized shear deformation theory for bending analysis of functionally graded plates. Appl. Math. Model., 30, 67-84, 2006.

[17] Elishakoff I., Gentilini C., Viola E., Three-dimensional analysis of an all-round clamped plate made of functionally graded materials. Acta Mech., 180(1-4), 21-36, 2005.

[18] Swaminathan K., Naveenkumar D.T., Zenkour A.M., Carrera E., Stress, vibration and buckling analyses of FGM plates-A state-of-the-art Review. Composite Structures, 120, 10-31, 2015.

[19] Winkler E. Theory of Elasticity and Strength of Materials. Dominicus, Prague, 1867.

[20] Pasternak P.L., On a new method of analysis of an elastic foundation by means of two foundation constants. Cosudarstrennoe Izdatelstvo Literaturi po Stroitelstvu i Arkhitekture, Moscow, USSR, 1-56, 1954.

[21] Vallabhan C.V.G., Straughan W.T., Das Y.C., Refined Model of Analysis of Plates of Elastic Foundations. Journal of Engineering Mechanics, 117(12), 2830-2844, 1994.

[22] Celik M., Saygun A., A method for the analysis of plates on a two-parameter foundation. Int. J. of Solids and Str., 36, 2891-2915, 1999.

[23] Xiang Y., Wang C.M., Kitipornchai S., Exact vibration solution for initially stressed Mindlin plates on Pasternak foundation. Int. J. Mech. Sci., 36(4), 311-316, 1994. 
[24] Omurtag M.H., Ozutok A., Akoz A.Y., Free vibration analysis of Kirchhoff plates resting on elastic foundation by mixed finite element formulation based on Gateaux differential. Int. J. Numer. Methods Eng., 40(2), 295-317, 1997.

[25] Matsunaga H. Vibration and stability of thick plates on elastic foundations. ASCE J. Eng. Mech., 126(1), 27-34,2000.

[26] Zhou D., Cheung Y.K., Lo S.H., Au F.T.K., Three-dimensional vibration analysis of rectangular thick plates on Pasternak foundations. Int. J. Numer. Methods. Eng., 59(10), 1313-1334, 2004.

[27] Shen H.S., Postbuckling analysis of composite laminated plates on two-parameter elastic foundations. Int. J. Mech. Sci., 37(12), 1307-131, 1995.

[28] Huang Z.Y., Lü C.F., Chen W.Q., Benchmark solutions for functionally graded thick plates resting on Winkler-Pasternak elastic foundations. Composite Structures, 85, 95-104, 2008.

[29] Lee W.H., Han S.C., Park W.T., A refined higher order shear and normal deformation theory for E-,P-, and S-FGM plates on Pasternak elastic foundation. Composite Structures, 122, 330-342, 2015.

[30] Tajeddini V., Ohadi A., Sadighi M., Three-dimensional free vibration of variable thickness thick circular and annular isotropic and functionally graded plates on Pasternak foundation. Int. J. Mech. Sci., 53(4), 300-308, 2011.

[31] Baferani A.H., Saidi A.R., Ehteshami H., Accurate solution for free vibration analysis of functionally graded thick rectangular plates resting on elastic foundation. Composite Structures, 93(7), 1842-1853, 2011.

[32] Malekzadeh P., Golbahar Haghighi M.R., Atashi M.M., Free vibration analysis of elastically supported functionally graded annular plates subjected to thermal environment. Meccanica, 46, 893-913, 2011.

[33] Thai H.T., Choi D.H., A refined shear deformation theory for free vibration of functionally graded plates on elastic foundation. Composites Part B, 43, 2335-2347, 2012.

[34] Mansouri M.H., Shariyat M., Differential quadrature thermal buckling analysis of general quadrilateral orthotropic auxetic FGM plates on elastic foundations. ThinWalled Structures, 112, 194-207, 2017.

[35] Hamarat M.A., Dynamic analysis of structures resting on two parameter elastic foundation. MSc Dissertation, Istanbul Technical University, Istanbul, 2012.

[36] Hamarat M.A., Çalık-Karaköse Ü.H., Orakdöğen E., Seismic Analysis of Structures Resting on Two Parameter Elastic Foundation. $15^{\text {th }}$ World Conference on Earthquake Engineering. Lisbon, Portugal, September, 2012. 
[37] Kutlu A., Analysis of free vibrations of Mindlin plates resting on arbitrarily orthotropic Pasternak foundation with mixed finite elements. MSc Dissertation, Istanbul Technical University, Istanbul, 2007.

[38] Kutlu A., Omurtag M.H., Large deflection bending analysis of elliptic plates on orthotropic elastic foundation with mixed finite element method, International Journal of Mechanical Sciences, 65, 64-74, 2012.

[39] Kutlu A., Ugurlu B., Omurtag M.H., Ergin A., Dynamic response of Mindlin plates resting on arbitrarily orthotropic Pasternak foundation and partially in contact with fluid. Ocean Engineering, 42,112-125, 2012.

[40] Kolahchi R., Safari M., Esmailpour M., Dynamic stability analysis of temperaturedependent functionally graded CNT-reinforced visco-plates resting on orthotropic elastomeric medium. Composite Structures, 150, 255-265, 2016.

[41] Heydari M. M., Bidgoli A. H., Golshani H. R., Beygipoor G., Davoodi, A., Nonlinear bending analysis of functionally graded CNT-reinforced composite Mindlin polymeric temperature-dependent plate resting on orthotropic elastomeric medium using GDQM. Nonlinear Dynamics, 79(2), 1425- 1441, 2015.

[42] Arani A. G., Cheraghbak A., Kolahchi R., Dynamic buckling of FGM viscoelastic nanoplates resting on orthotropic elastic medium based on sinusoidal shear deformation theory. Structural engineering and mechanics: An international journal, 60(3), 489-505, 2016.

[43] SAP2000, v18., Integrated Finite Elements Analysis and Design of Structures, Computers and Structures. p. Inc, Berkeley, CA, 2016.

[44] Elmacı Ş., Spectral analysis and determination of free vibration characteristics of quadratic plates resting on arbitrarily orthotropic two parameter elastic foundation. MSc Dissertation, Istanbul Technical University, Istanbul, 2019.

[45] Aykılıç B., Spectral analysis of circular and elliptic plates resting on arbitrarily orthotropic Pasternak type foundation. MSc Dissertation, Istanbul Technical University, Istanbul, 2019.

[46] Lam K.Y., Wang C.M., He X.Q., Canonical exact solution for Levy-plates on two parameter foundation using Green's functions. Eng. Struct., 22(4),364-378, 2000. 